\title{
Condutividade elétrica e crescimento do milho em solos contrastantes sob aplicação de diversos níveis de calagem
}

\author{
Davi Lopes do Carmo(1) e Carlos Alberto Silva ${ }^{(2)}$
}

\begin{abstract}
(1)Universidade Federal de Viçosa, Departamento de Fitotecnia, CEP 36570-900 Viçosa, MG, Brasil. E-mail: davigoldan@yahoo.com.br (2)Universidade Federal de Lavras, Departamento de Ciência do Solo, Caixa Postal 3037, CEP 37200-000 Lavras, MG, Brasil. E-mail: csilva@dcs.ufla.br
\end{abstract}

Resumo - O objetivo deste trabalho foi avaliar o efeito da aplicação de níveis crescentes de calagem sobre a condutividade elétrica de solos contrastantes quanto à textura e aos teores de matéria orgânica, assim como o grau de associação da condutividade elétrica e da concentração de nutrientes com a massa de matéria seca total de milho. A condutividade elétrica e os teores disponíveis de macro e micronutrientes foram determinados, tendo-se calculado a concentração de nutrientes de solos incubados com doses crescentes de $\mathrm{CaCO}_{3}+\mathrm{MgCO}_{3}$. Determinou-se o grau de associação da condutividade elétrica com os atributos de fertilidade e de acidez de cada solo e com a massa de matéria seca de milho, cultivado por 35 dias em vaso. A condutividade elétrica aumenta com o acréscimo dos níveis de calagem e se correlaciona positivamente ao $\mathrm{pH}$, à saturação por bases, aos teores de $\mathrm{Ca}^{2+}$ e de $\mathrm{Mg}^{2+}$ e à concentração de nutrientes. Não há uma equação universal que relacione os dados de condutividade elétrica com os atributos dos dez solos investigados e com a massa de matéria seca total de milho. Para cada solo, há relação direta entre a condutividade elétrica e a massa de matéria seca de milho, e entre a condutividade elétrica e a concentração de nutrientes.

Termos para indexação: atributos de acidez do solo, disponibilidade de nutrientes, matéria orgânica, solução do solo, textura do solo.

\section{Electrical conductivity and corn growth in contrasting soils affected by liming application at various levels}

\begin{abstract}
The objective of this work was to evaluate the effect of the application of increasing liming levels on the electrical conductivity of soils contrasting for texture and contents of soil organic matter, as well as the relationship of soil electrical conductivity and soil nutrient concentration with corn dry matter. Soil electrical conductivity and the available contents of macro- and micronutrients were determined; and the nutrient concentration was calculated for soil samples incubated with increasing rates of $\mathrm{CaCO}_{3}+\mathrm{MgCO}_{3}$. The degree of association of soil electrical conductivity with the fertility and acidity properties of each soil, and with the dry matter of corn, grown during 35 days in pots, was determined. Soil electrical conductivity increases with increasing liming levels and correlates positively with $\mathrm{pH}$, base saturation, $\mathrm{Ca}^{2+}$ and $\mathrm{Mg}^{2+}$ contents, and with nutrient concentration. There is no universal mathematical equation that relates soil electrical conductivity with the properties of the ten researched soils and with total dry matter of corn. For each soil, there is a direct relationship between soil electrical conductivity and corn dry matter, and between electrical conductivity and nutrient concentration.
\end{abstract}

Index terms: soil acidity properties, nutrient availability, organic matter, soil solution, soil texture.

\section{Introdução}

A calagem é uma prática rotineiramente adotada nas lavouras brasileiras, e sabe-se que seus efeitos são relacionados ao aumento do $\mathrm{pH}$, aos teores trocáveis de $\mathrm{Ca}$ e $\mathrm{Mg}$, à capacidade de troca de cátions e à redução do Al tóxico às plantas (Raij, 2011). Além disso, com o acréscimo dos níveis de aplicação, a calagem interfere em diferentes processos bioquímicos do solo, causando aumento da taxa de nitrificação e de mineralização da matéria orgânica (MO) (Silva et al., 1994). Com a prática da calagem, há aumento da concentração de íons e sais, como consequência da dose de corretivo aplicada, e da magnitude dos efeitos da calagem sobre os processos do solo que regulam a disponibilidade de nutrientes. Porém, conforme o valor do $\mathrm{pH}$ e os níveis de $\mathrm{Ca}$ adicionados ao solo, pode haver supercalagem, o 
que pode implicar em menor concentração de íons no solo, em razão da precipitação de fosfato com cálcio, neutralização de $\mathrm{Al}^{3+}$ e do fluxo de íons da solução para a fase sólida, pela maior adsorção de metais aos coloides do solo. Além disso, a magnitude das taxas de nitrificação e de mineralização da $\mathrm{MO}$ - processos regulados pela textura e teores de $\mathrm{MO}$ do solo - e as quantidades de corretivo controlam, também, a concentração de íons e sais nos solos corrigidos. Essa mudança da disponibilidade de íons e sais no solo pode afetar a condutividade elétrica (CE) do solo, o que permite inferir que a condução de corrente elétrica ocorre de acordo com a disponibilidade e a concentração de sais e íons associados às fases sólida e líquida do solo (Heiniger et al., 2003).

No solo, a CE é regulada pelas concentrações de $\mathrm{H}^{+}$, $\mathrm{OH}^{-}$, teores trocáveis de $\mathrm{Ca}, \mathrm{Mg}, \mathrm{K}, \mathrm{N}-\mathrm{NH}_{4}{ }^{+}, \mathrm{N}_{-} \mathrm{NO}_{3}{ }^{-}$, íons fosfato e sulfato, teores de espécies de $\mathrm{Al}$ solúveis, disponibilidade de micronutrientes etc. No solo, a relação direta entre a concentração de íons e o fluxo de corrente elétrica explica o fato de a CE do solo já ter sido utilizada para estimar a produtividade das culturas (Johnson et al., 2005), delimitar unidades de manejo do solo (Moral et al., 2010), estimar concentrações de nutrientes (Heiniger et al., 2003; Peralta \& Costa, 2013), avaliar a variabilidade espacial de atributos do solo (Moral et al., 2010) e como índice para a recomendação de adubação nitrogenada (Lund et al., 2001; Peralta et al., 2015). A magnitude da relação da CE com atributos do solo e com a produtividade das culturas depende do teor de argila do solo (Lesch et al., 2005; Moral et al., 2010). Há correlação positiva da CE com o pH (Fernandes et al., 2008; Moral et al., 2010), $\mathrm{Ca}^{2+}$ (McBride et al., 1990; Fernandes et al., 2008; Peralta \& Costa, 2013), $\mathrm{Mg}^{2+}$ (Fernandes et al., 2008; Peralta \& Costa, 2013) e com a MO (Heiniger et al., 2003; Corwin \& Lesch, 2005; Peralta \& Costa, 2013). O valor da CE em avaliar a disponibilidade de nutrientes no solo é condicionado à capacidade de se avaliarem mudanças da textura, da CTC e do teor de húmus do solo (Heiniger et al., 2003).

A calagem promove alterações das taxas de decomposição da $\mathrm{MO}$, da nitrificação, da solubilização ou da precipitação de nutrientes e de fertilizantes, do fluxo de nutrientes entre as fases líquida e sólida, da densidade de cargas na superfície de coloides, etc (Prado \& Natale, 2008; Yao et al., 2009; Raij, 2011). Assim, é grande a chance de a CE se correlacionar aos atributos de acidez e à concentração e à disponibilidade de cátions e ânions no solo e, indiretamente, explicar parte da variação da massa de matéria seca de milho sob efeito de aplicações de calagem. A magnitude de aumento da $\mathrm{CE}$ com os níveis de calagem é dependente do solo, uma vez que é condicionada pela textura e pela MO.

O objetivo deste trabalho foi avaliar a influência da aplicação de níveis crescentes de calagem sobre a condutividade elétrica de solos contrastantes quanto à textura e aos teores de matéria orgânica, assim como o grau de associação da condutividade elétrica e da concentração de nutrientes com a massa de matéria seca total de milho.

\section{Material e Métodos}

Para este estudo, selecionaram-se 10 classes de solos contrastantes do sul do Estado de Minas Gerais, com ampla variação de textura e de teores de matéria orgânica descritos na Tabela 1.

As amostras foram coletadas na camada de $0-20 \mathrm{~cm}$ de profundidade e secas ao ar (TFSA), destorroadas e peneiradas em malha de $2 \mathrm{~mm}$, para a caracterização química e textural. Analisaram-se os seguintes parâmetros: $\mathrm{pH}$ em água; $\mathrm{CE}$; teores de $\mathrm{Ca}^{2+}, \mathrm{Mg}^{2+}, \mathrm{Al}^{3+}$; $\mathrm{C}$ total (CT); MO; $\mathrm{N}$ total $(\mathrm{N}) ; \mathrm{H}+\mathrm{Al} ; \mathrm{N}_{-} \mathrm{NH}_{4}{ }^{+} ; \mathrm{N}_{-} \mathrm{NO}_{3}{ }^{-}$; $\mathrm{S}$-sulfato; $\mathrm{K}^{+}$; P-Mehlich-1; $\mathrm{P}$ remanescente; teores de $\mathrm{Zn}, \mathrm{Fe}, \mathrm{Mn}, \mathrm{Cu}$ e B; saturação por $\mathrm{Al}^{3+}(\mathrm{m})$; saturação por bases $(\mathrm{V})$; capacidade de troca de cátions (CTC) em pH 7; e CTC efetiva, em condição natural, conforme protocolos analíticos descritos em Silva (2009).

Na determinação do $\mathrm{pH}$ em água e da CE, utilizou-se a relação solo:água de 1:2,5 $\left(10 \mathrm{~cm}^{3}\right.$ de TFSA: $25 \mathrm{~mL}$ de água). A mistura solo-água foi agitada por $30 \mathrm{~min}$, mantida em repouso por $30 \mathrm{~min}$ e agitada por $30 \mathrm{~s}$. Em seguida, procedeu-se à leitura do $\mathrm{pH}$ e da $\mathrm{CE}$. A CE foi determinada em condutivímetro TEC-4MP (Tecnal Equipamentos Científicos, Piracicaba, SP). Os teores de $\mathrm{Ca}^{2+}, \mathrm{Mg}^{2+}$ e $\mathrm{Al}^{3+}$ foram extraídos com solução de $\mathrm{KCl}$ a $1 \mathrm{~mol} \mathrm{~L}^{-1}$; os teores de $\mathrm{P}, \mathrm{K}^{+}, \mathrm{Fe}, \mathrm{Zn}$, $\mathrm{Mn}$ e $\mathrm{Cu}$ foram extraídos com a solução Mehlich-1 ( $\left.\mathrm{HCl} 0,05 \mathrm{~mol} \mathrm{~L}^{-1}+\mathrm{H}_{2} \mathrm{SO}_{4} 0,0125 \mathrm{~mol} \mathrm{~L}^{-1}\right)$; o B foi extraído em água quente; e os teores de $\mathrm{MO}$ foram extraídos por oxidação em $\mathrm{Na}_{2} \mathrm{Cr}_{2} \mathrm{O}_{7} 4 \mathrm{~N}+\mathrm{H}_{2} \mathrm{SO}_{4} 10 \mathrm{~N}$. Os teores de $\mathrm{K}$ foram determinados por fotometria de chama, e os de $\mathrm{Ca}^{2+}, \mathrm{Mg}^{2+}, \mathrm{Fe}, \mathrm{Zn}, \mathrm{Mn}$ e $\mathrm{Cu}$, em espectrofotômetro de absorção atômica; os teores de $\mathrm{B}, \mathrm{P}, \mathrm{S}$ e $\mathrm{MO}$ foram determinados por colorimetria. A acidez potencial $(\mathrm{H}+\mathrm{Al})$ foi determinada de forma

Pesq. agropec. bras., Brasília, v.51, n.10, p.1762-1772, out. 2016 DOI: $10.1590 / \mathrm{S} 0100-204 \mathrm{X} 2016001000008$ 
indireta, em razão da determinação do $\mathrm{pH}$ em solução tampão SMP. Os teores de C total (CT) foram determinados por combustão seca, em analisador Vario TOC (Elementar Analysenysteme, Langenselbold, Hesse, Alemanha). A análise granulométrica do solo foi realizada pelo método de Bouyoucos (Claessen, 1997), tendo-se utilizado $\mathrm{NaOH}$ a $0,1 \mathrm{~mol} \mathrm{~L}^{-1}$ como dispersante químico.

Após a caracterização do solo em condição natural, realizou-se a calagem, com base na curva de neutralização de acidez previamente estabelecida, para atingir níveis crescentes de $\mathrm{pH}$-alvo em cada solo (Tabela 2). Utilizaram-se os carbonatos de cálcio $\left(\mathrm{CaCO}_{3}\right)$ e de magnésio $\left(\mathrm{MgCO}_{3}\right)$ à proporção de 3:1, respectivamente. Após a mistura com o corretivo de acidez, os solos permaneceram incubados por 30 dias, tendo-se mantido, durante esse período, a umidade do solo próxima de $70 \%$ da capacidade de campo.

$\mathrm{O}$ delineamento inteiramente casualizado foi utilizado em arranjo fatorial $10 \times 5$, representado pela combinação de 10 solos por cinco níveis de saturação por bases $(\mathrm{V})$, com o uso de três repetições, no total de 150 parcelas experimentais. Em vasos de 1,8 L, colocou-se $1,3 \mathrm{~kg}$ de solo com as doses variáveis de carbonatos. Decorridos 30 dias de incubação com carbonatos, realizaram-se adubações com $\mathrm{P}, \mathrm{K}$ e micronutrientes ( $\mathrm{B}, \mathrm{Zn}, \mathrm{Fe}, \mathrm{Cu}$ e $\mathrm{Mn}$ ), recomendadas para cultivo em vasos (Novais et al., 1991), que foram incubados por mais 15 dias. A adubação com $\mathrm{P}$ foi realizada com duas fontes, das quais $40 \%$ do $\mathrm{P}$ foi fornecido via $\mathrm{Ca}\left(\mathrm{H}_{2} \mathrm{PO}_{4}\right)_{2}$, e $60 \%$, via $\mathrm{KH}_{2} \mathrm{PO}_{4}$, com a adição total de $250 \mathrm{mg} \mathrm{kg}^{-1}$ de $\mathrm{P}$ ao NQ e ao $\mathrm{SXd}_{2}$, e $400 \mathrm{mg} \mathrm{kg}^{-1}$ de $\mathrm{P}$ aos demais solos. A adubação com $\mathrm{K}$ foi realizada somente nas amostras do NQ e $\mathrm{SXd}_{2}$, com adição de $114 \mathrm{mg} \mathrm{kg}^{-1}$, tendo-se utilizado a fonte $\mathrm{KCl}$ p.a., pois a adubação com $\mathrm{K}$ para os demais solos foi feita quando se forneceu $60 \%$ do $\mathrm{P}$ via $\mathrm{KH}_{2} \mathrm{PO}_{4}$. As adubações com micronutrientes $-6 \mathrm{mg} \mathrm{kg}^{-1} \mathrm{de}$ $\mathrm{Zn}, 5,5 \mathrm{mg} \mathrm{kg}^{-1}$ de $\mathrm{Mn}, 4 \mathrm{mg} \mathrm{kg}^{-1}$ de $\mathrm{Fe}, 2 \mathrm{mg} \mathrm{kg}^{-1}$ de $\mathrm{Cu}$, e $1 \mathrm{mg} \mathrm{kg}^{-1}$ de $\mathrm{B}$ - foram feitas a partir das

Tabela 1. Caracterização química e textural dos solos investigados em condições naturais.

\begin{tabular}{|c|c|c|c|c|c|c|c|c|c|c|c|c|c|c|}
\hline Solo $^{(1)}$ & $\begin{array}{c}\mathrm{pH} \\
\text { em água }\end{array}$ & $\begin{array}{c}\mathrm{K}^{+} \\
---(\mathrm{m} \\
\end{array}$ & $\begin{array}{c}P \\
\left.\mathrm{n}^{-3}\right)--- \\
\end{array}$ & $\mathrm{Ca}^{2+}$ & $\mathrm{Mg}^{2+}$ & $\begin{array}{l}\mathrm{Al}^{3+} \\
--(\mathrm{cm}\end{array}$ & $\begin{array}{l}\mathrm{H}+\mathrm{Al} \\
\left(\mathrm{m}^{-3}\right)--\end{array}$ & t & $\mathrm{T}$ & $\begin{array}{c}\mathrm{V} \\
-\end{array}$ & $\begin{array}{c}\mathrm{m} \\
-(\%) \\
\end{array}$ & CT & $\begin{array}{c}\text { MO } \\
\left(\text { dag kg }^{-1}\right)\end{array}$ & $\begin{array}{l}\text { N-total } \\
\left(\mathrm{g} \mathrm{kg}^{-1}\right)\end{array}$ \\
\hline$\overline{\mathrm{OX}}$ & 4,2 & 65 & 12 & 0,8 & 0,3 & 2,8 & 17 & 4,1 & 18,0 & 7 & 69 & 7,4 & 7,1 & 5,5 \\
\hline LVd1 & 4,3 & 51 & 1,8 & 0,6 & 0,2 & 1,9 & 15 & 2,8 & 16,0 & 6 & 68 & 4,6 & 6,2 & 4,5 \\
\hline NQ & 5,2 & 39 & 14 & 0,4 & 0,1 & 0,6 & 4,0 & 1,2 & 4,6 & 14 & 53 & 0,9 & 1,6 & 1,1 \\
\hline LHd & 5,5 & 101 & 4,2 & 3,2 & 1,2 & 0,4 & 7,9 & 5,1 & 12,0 & 35 & 8,3 & 6,5 & 7,1 & 5,9 \\
\hline SXd1 & 5,1 & 27 & 1,3 & 1,2 & 0,2 & 0,6 & 4,2 & 2,0 & 5,7 & 24 & 31 & 1,6 & 2,0 & 1,6 \\
\hline LVd2 & 4,7 & 40 & 1,9 & 0,4 & 0,1 & 1,0 & 7,1 & 1,6 & 8,1 & 8 & 63 & 2,7 & 3,2 & 3,3 \\
\hline $\mathrm{CXd} 2$ & 5,0 & 53 & 2,0 & 0,5 & 0,2 & 0,6 & 6,3 & 1,5 & 7,6 & 12 & 45 & 2,2 & 3,7 & 3,1 \\
\hline $\mathrm{SXd} 2$ & 5,6 & 95 & 1,9 & 2,5 & 0,5 & 0,2 & 3,8 & 3,5 & 7,1 & 46 & 5,7 & 2,8 & 3,4 & 3,1 \\
\hline CXd1 & 5,6 & 59 & 2,6 & 2,3 & 0,4 & 0,3 & 4,2 & 3,1 & 7,0 & 40 & 8,7 & 3,0 & 3,7 & 3,3 \\
\hline LVe & 5,5 & 65 & 2,6 & 4,9 & 0,8 & 0,1 & 5,1 & 6,0 & 11,0 & 55 & 2,1 & 4,2 & 6,1 & 5,0 \\
\hline & $\begin{array}{c}\mathrm{CE} \\
\left(\mu \mathrm{S} \mathrm{cm}^{-1}\right)\end{array}$ & & & $\mathrm{Zn}$ & $\mathrm{Fe}$ & $\begin{array}{c}\mathrm{Mn} \\
--(\mathrm{m} \\
\end{array}$ & $\begin{array}{c}\mathrm{Cu} \\
\left.\mathrm{n}^{-3}\right)-\cdot \\
\end{array}$ & B & S & Argila & $\begin{array}{c}\text { Silte } \\
\left(\mathrm{g} \mathrm{kg}^{-1}\right)\end{array}$ & Areia & $\begin{array}{l}\mathrm{N}-\mathrm{NO}_{4}{ }^{+} \\
----(\mathrm{mg} \\
\end{array}$ & $\begin{array}{l}\mathrm{N}-\mathrm{NO}_{3}- \\
\left.\mathrm{kg}^{-1}\right)--- \\
\end{array}$ \\
\hline $\mathrm{OX}$ & 337 & & & 0,8 & 27 & 6,2 & 0,7 & 0,2 & 11 & 500 & 180 & 320 & 22 & 122 \\
\hline LVd1 & 100 & & & 1,1 & 149 & 5,6 & 1,2 & 0,1 & 12 & 750 & 110 & 140 & 33 & 33 \\
\hline NQ & 35 & & & 0,6 & 79 & 3,7 & 0,3 & 0,1 & 5,1 & 40,0 & 30,0 & 930 & 22 & 28 \\
\hline LHd & 76 & & & 2,2 & 47 & 16 & 0,7 & 0,1 & 7,5 & 510 & 150 & 340 & 35 & 23 \\
\hline SXd1 & 37 & & & 1,2 & 106 & 6,6 & 0,5 & 0,1 & 6,2 & 250 & 160 & 590 & 25 & 22 \\
\hline $\mathrm{LVd} 2$ & 62 & & & 0,6 & 87 & 3,7 & 0,9 & 0,1 & 11 & 500 & 130 & 370 & 42 & 27 \\
\hline $\mathrm{CXd} 2$ & 42 & & & 1,3 & 49 & 52 & 2,7 & 0,1 & 6,4 & 440 & 330 & 230 & 57 & 24 \\
\hline $\mathrm{SXd} 2$ & 69 & & & 1,3 & 123 & 16 & 0,7 & 0,2 & 9,5 & 150 & 100 & 750 & 42 & 27 \\
\hline CXd1 & 62 & & & 2,8 & 116 & 22 & 1,1 & 0,1 & 9,9 & 350 & 190 & 460 & 29 & 27 \\
\hline LVe & 116 & & & 1,9 & 78 & 16 & 1,0 & 0,2 & 14 & 480 & 160 & 360 & 32 & 31 \\
\hline
\end{tabular}

(1)Sistema Brasileiro de Classificação de Solos (Embrapa, 2013). OX, Organossolo Háplico (-21,103101; -45,535131); LVd 1 , Latossolo Vermelho distrófico (-21,294266; -44,625566); NQ, Neossolo Quartzarênico (-21,294266; -44,625566); LHd, Latossolo Húmico distrófico (-21,228875; -44,967709); SXd Planossolo Háplico distrófico (-21,217654; -44,972644); $\mathrm{LVd}_{2}$, Latossolo Vermelho distrófico (-21,227175; -44,983888); CXd 2 , Cambissolo Háplico Tb distrófico; $\mathrm{SXd}_{2}$, Planossolo Háplico distrófico (-21,2891; -44,8636); CXd ${ }_{1}$, Cambissolo Háplico Tb distrófico (-21,228235; -44,983824); LVe, Latossolo Vermelho eutrófico (-21,229535; -44,097493). t, Capacidade de troca de cátions efetiva; T, capacidade de troca de cátions a pH 7; V, saturação por bases; m, saturação por alumínio; CT, carbono total; MO, matéria orgânica; P, fósforo extraível em solução de Mehlich-1; P-rem, P remanescente; CE, condutividade elétrica. 
seguintes fontes, respectivamente: $\mathrm{ZnSO}_{4} .7 \mathrm{H}_{2} \mathrm{O}$, $\mathrm{MnCl}_{2} \cdot 4 \mathrm{H}_{2} \mathrm{O}, \mathrm{FeSO}_{4} .7 \mathrm{H}_{2} \mathrm{O}, \mathrm{CuSO}_{4} .5 \mathrm{H}_{2} \mathrm{O}$ e $\mathrm{H}_{3} \mathrm{BO}_{3}$. As adubações com $\mathrm{N}$ foram feitas com $300 \mathrm{mg} \mathrm{kg}^{-1}$, dos quais $100 \mathrm{mg} \mathrm{kg}^{-1}$ logo após o plantio, com adição de $50 \mathrm{mg} \mathrm{kg}^{-1}$ de $\mathrm{N}$ como $\mathrm{NH}_{4} \mathrm{NO}_{3}$, e $50 \mathrm{mg} \mathrm{kg}^{-1}$ de $\mathrm{N}$ na forma de $\left(\mathrm{NH}_{4}\right)_{2} \mathrm{SO}_{4}$, seguidas de mais duas adubações

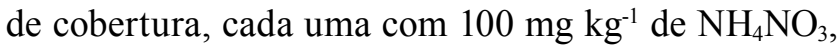
aos 7 e 14 dias após plantio.

Antes da semeadura do milho e após a incubação dos solos com carbonatos e nutrientes adicionados, com exceção do $\mathrm{N}$, foi feita a coleta de solo em cada parcela e a caracterização química, conforme Silva (2009). Analisaram-se: $\mathrm{pH}$ em água; $\mathrm{CE}$; teores de $\mathrm{Ca}^{2+}, \mathrm{Mg}^{2+}, \mathrm{Al}^{3+} ; \mathrm{C}$ total $(\mathrm{CT}) ; \mathrm{MO} ; \mathrm{N}$ total $(\mathrm{N})$; $\mathrm{H}+\mathrm{Al},{\mathrm{N}-\mathrm{NH}_{4}{ }^{+} \text {e N-NO}}_{3}^{-}$; S-sulfato; $\mathrm{K}^{+}$; P Mehlich-1; P remanescente; teores de $\mathrm{Zn}, \mathrm{Fe}, \mathrm{Mn}, \mathrm{Cu}$ e $\mathrm{B}$; saturação por $\mathrm{Al}^{3+}(\mathrm{m})$; saturação por bases $(\mathrm{V})$; capacidade de troca de cátions (CTC) em pH 7; e CTC efetiva. Analisaram-se também as concentrações de nutrientes $[\mathrm{Nu}]$ em cada solo, tendo-se considerado a soma dos teores disponíveis $\left(\mathrm{g} \mathrm{dm}^{-3}\right)$ de $\mathrm{N}$ (amônio e nitrato), $\mathrm{P}$, $\mathrm{K}, \mathrm{Ca}, \mathrm{Mg}, \mathrm{S}, \mathrm{Zn}, \mathrm{Fe}, \mathrm{Mn}, \mathrm{Cu}$ e B.

Em seguida, realizou-se a semeadura de duas sementes de milho híbrido DKB 390 VT PRO 2 por vaso, à profundidade de $2 \mathrm{~cm}$. Após a emergência, realizou-se o desbaste, tendo-se deixado uma planta em cada vaso. $\mathrm{O}$ experimento foi realizado em casa de vegetação, do Departamento de Ciência do Solo, da Universidade Federal de Lavras (Ufla), pelo período de 35 dias. Ao final do período experimental, as plantas foram colhidas, lavadas em água deionizada e acondicionadas em sacos de papel. Em seguida, determinou-se a massa de matéria seca total (MST), a partir da massa da raiz + parte aérea secas a $70^{\circ} \mathrm{C}$. A MST foi determinada pela pesagem das amostras em balança de precisão $(0,001 \mathrm{~g})$, e o resultado foi expresso em gramas de matéria seca por vaso.

Os dados foram submetidos à análise de variância, pela aplicação do teste $\mathrm{F}$, a $5 \%$ de probabilidade e, quando significativo, realizou-se a análise de regressão, pelo programa Sisvar (Universidade Federal de Lavras, Lavras, MG).

\section{Resultados e Discussão}

As doses de carbonatos, aplicadas aos 10 solos, promoveram aumentos significativos da $\mathrm{CE}, \mathrm{pH}$, saturação por bases (V) e dos teores de $\mathrm{Ca}^{2+}$ e $\mathrm{Mg}^{2+}$ (Figura 1). Há uma especificidade dessas relações para cada solo, o que pode ser justificado e se explica pela ampla variação dos teores da $\mathrm{MO}$ e da textura dos 10 solos investigados. Heiniger et al. (2003) mostraram que a textura, o teor de $\mathrm{MO}$ e a CTC são atributos que regulam a $\mathrm{CE}$ do solo, de modo que a alteração da disponibilidade de nutrientes no solo só pode ser predita pela $\mathrm{CE}$ se as mudanças dos atributos mencionados forem corretamente avaliadas. No presente estudo, não há uma equação universal que relacione dados de CE e níveis de calagem, para o conjunto de solos investigados. Segundo Amaral et al. (2004) e Chaves et al. (1997), há aumento da CE do solo em razão da adição de doses crescentes

Tabela 2. Níveis crescentes de pH-alvo e doses de carbonatos $\left(\mathrm{CaCO}_{3}+\mathrm{MgCO}_{3}\right)$ aplicadas nos 10 solos investigados.

\begin{tabular}{|c|c|c|c|c|c|c|c|c|c|c|}
\hline \multirow[t]{2}{*}{$\overline{\text { Solo }^{(1)}}$} & \multicolumn{5}{|c|}{ Níveis de pH-alvo } & \multicolumn{5}{|c|}{$\mathrm{Dose}^{(2)} \mathrm{de} \mathrm{CaCO}_{3}+\mathrm{MgCO}_{3}\left(\mathrm{~g} \mathrm{~kg}^{-1}\right)$} \\
\hline & $\mathrm{pH}$ atual & $\mathrm{pH} 1$ & $\mathrm{pH} 2$ & $\mathrm{pH} 3$ & $\mathrm{pH} 4$ & $\begin{array}{c}\text { Controle } \\
\text { (pH atual) }\end{array}$ & $\mathrm{pH} 1$ & $\mathrm{pH} 2$ & $\mathrm{pH} 3$ & $\mathrm{pH} 4$ \\
\hline$\overline{\mathrm{OX}}$ & 4,2 & 5,4 & 5,8 & 6,2 & 6,6 & 0 & 4,70 & 7,20 & 9,70 & 12,2 \\
\hline LVd1 & 4,3 & 5,4 & 5,9 & 6,2 & 6,7 & 0 & 1,70 & 3,40 & 5,10 & 8,00 \\
\hline NQ & 5,2 & 5,9 & 6,1 & 6,3 & 6,7 & 0 & 0,18 & 0,36 & 0,54 & 0,90 \\
\hline LHd & 5,5 & 5,7 & 5,9 & 6,2 & 6,7 & 0 & 1,70 & 3,35 & 6,65 & 8,28 \\
\hline SXd1 & 5,1 & 6,1 & 6,3 & 6,4 & 6,6 & 0 & 0,35 & 0,83 & 1,08 & 1,57 \\
\hline LVd2 & 4,7 & 5,8 & 6,0 & 6,4 & 6,6 & 0 & 0,46 & 0,99 & 2,07 & 2,61 \\
\hline $\mathrm{CXd} 2$ & 5,0 & 5,7 & 6,2 & 6,4 & 6,7 & 0 & 0,17 & 0,73 & 1,29 & 2,14 \\
\hline $\mathrm{SXd} 2$ & 5,6 & 6,0 & 6,2 & 6,4 & 6,7 & 0 & 0,32 & 0,67 & 1,03 & 1,39 \\
\hline CXd1 & 5,6 & 6,1 & 6,3 & 6,5 & 6,7 & 0 & 0,34 & 0,69 & 1,04 & 1,40 \\
\hline$\underline{\mathrm{LVe}}$ & 5,5 & 5,8 & 6,1 & 6,4 & 6,7 & 0 & 0,29 & 0,56 & 1,10 & 1,63 \\
\hline
\end{tabular}

${ }^{(1)}$ Sistema Brasileiro de classificação de solos (Santos, 2013). ${ }^{(2)}$ Relação estequiométrica de 3:1, considerando-se o poder de neutralização de cada carbonato. OX, Organossolo Háplico; $\mathrm{LVd}_{1}$, Latossolo Vermelho distrófico; NQ, Neossolo Quartzarênico; LHd, Latossolo Húmico distrófico; SXd Háplico distrófico; $\mathrm{LVd}_{2}$, Latossolo Vermelho distrófico; $\mathrm{CXd}_{2}$, Cambissolo Háplico Tb distrófico; $\mathrm{SXd}_{2}$, Planossolo Háplico distrófico; CXd $\mathrm{C}_{1}$-Cambissolo Háplico Tb distrófico; LVe, Latossolo Vermelho eutrófico. 

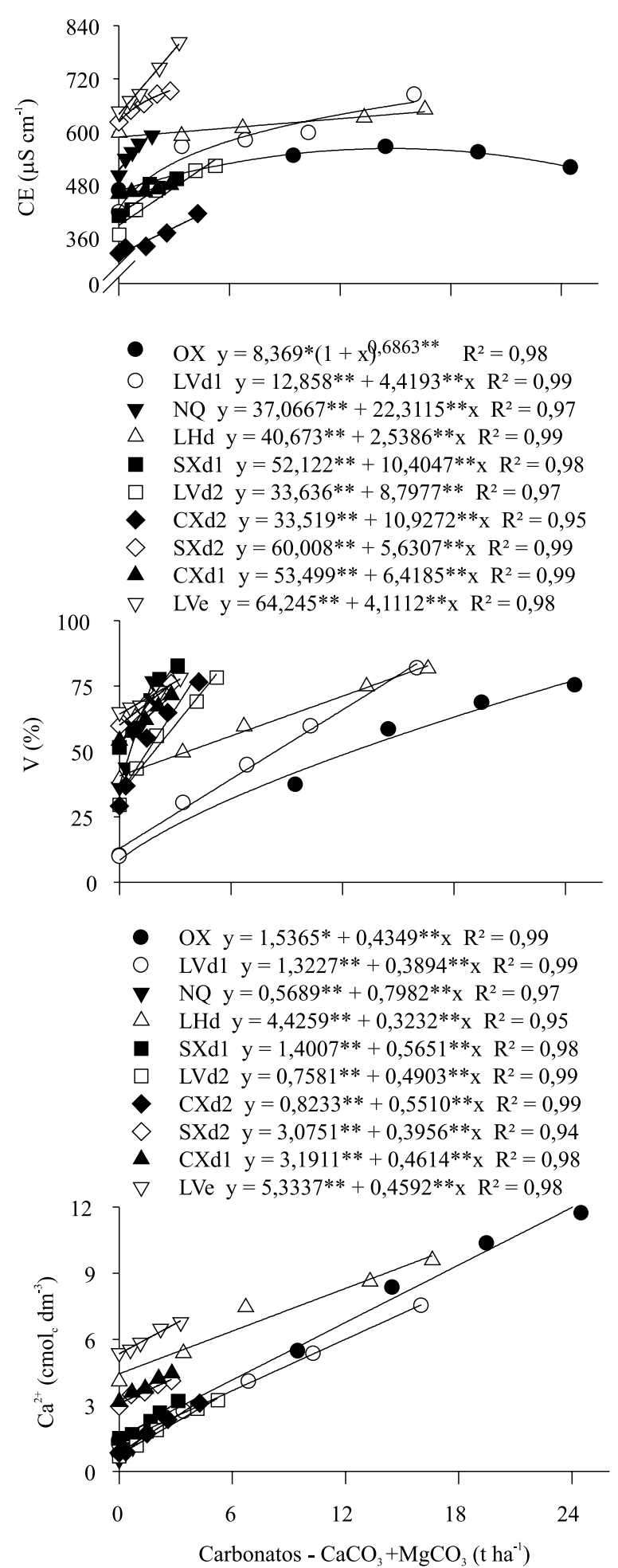

- OX $\mathrm{y}=466 * *+12,97 * * \mathrm{x}-0,440 * * \mathrm{x}^{2} \quad \mathrm{R}^{2}=0,99$

O LVd1 $\mathrm{y}=424,8^{* *}(1+\mathrm{x})^{0,1589 * *} \quad \mathrm{R}^{2}=0,95$

$\nabla \mathrm{NQ} \mathrm{y}=513,2 * *+48,127^{* *} \mathrm{x} \quad \mathrm{R}^{2}=0,92$

$\triangle \quad$ LHd $\mathrm{y}=587,6^{* *}+3,46^{* *} \mathrm{x} \quad \mathrm{R}^{2}=0,90$

SXd1 $\mathrm{y}=412,4 * *+28,38^{*} \mathrm{x} \quad \mathrm{R}^{2}=0,89$

$\operatorname{LVd} 2 \mathrm{y}=387,9^{* *}+28,43^{* *} \mathrm{x} \quad \mathrm{R}^{2}=0,93$

$\mathrm{CXd} 2 \mathrm{y}=322,6^{* *}+20,16^{* *} \mathrm{x} \quad \mathrm{R}^{2}=0,95$

$\mathrm{SXd} 2 \mathrm{y}=621,5^{* *}(1+\mathrm{x})^{0,0815^{* *}} \quad \mathrm{R}^{2}=0,99$

$\Delta \quad \mathrm{CXd1} \mathrm{y}=457,9^{* *}+6,65^{*} \mathrm{x} \quad \mathrm{R}^{2}=0,88$

$\nabla \quad$ LVe $\mathrm{y}=639,1^{* *}+48,69^{* *} \mathrm{x} \quad \mathrm{R}^{2}=0,99$

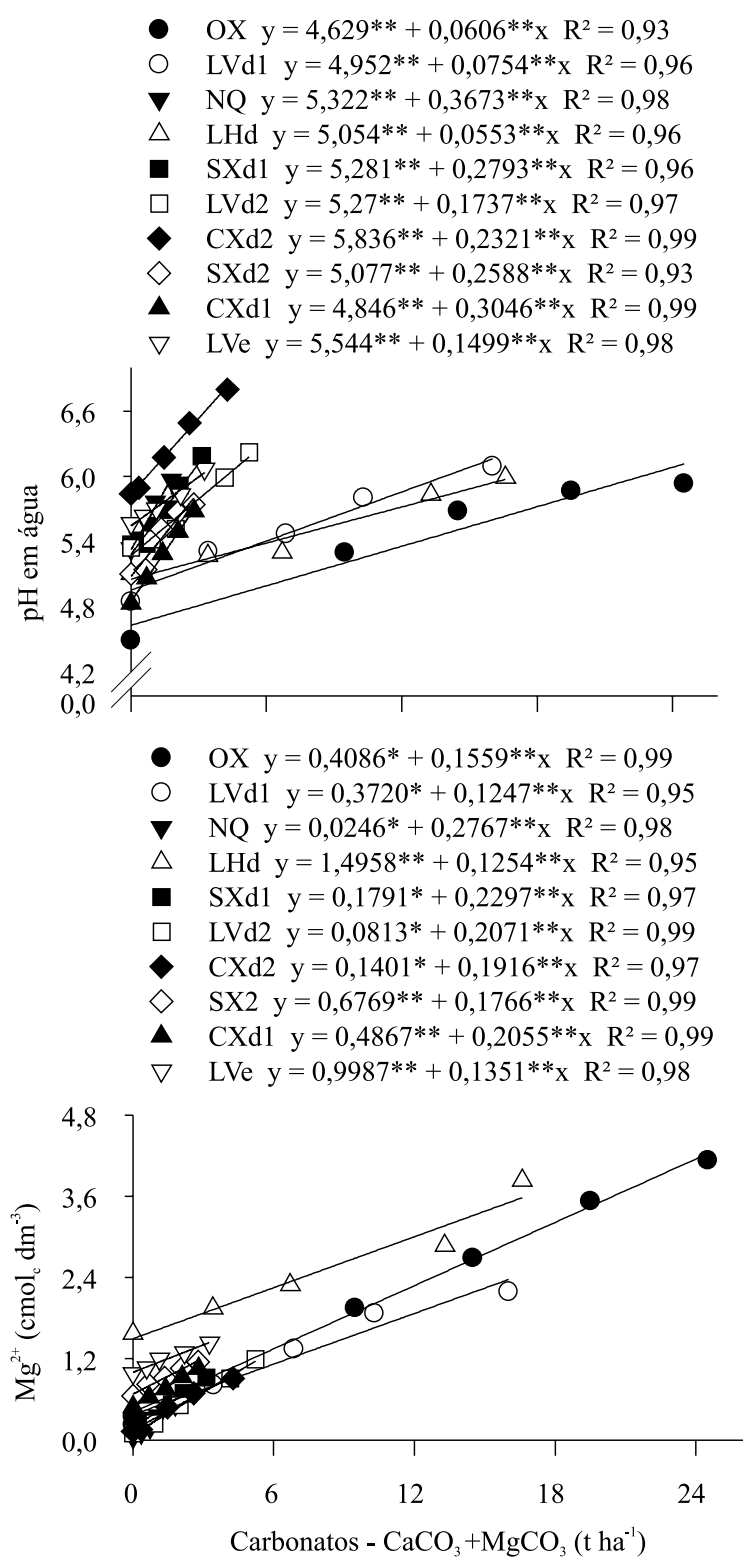

Figura 1. Efeito de doses de $\mathrm{CaCO}_{3}+\mathrm{MgCO}_{3}$ (3:1) sobre a condutividade elétrica (CE) e os atributos de acidez (V, $\mathrm{pH}$, $\mathrm{Ca}^{2+}$ e $\mathrm{Mg}^{2+}$ ), em dez tipos de solos. *e** Significativo a 1 e 5\%, respectivamente, pelo teste F. OX, Organossolo Háplico; $\mathrm{LVd}_{1}$, Latossolo Vermelho distrófico; NQ, Neossolo Quartzarênico; LHd, Latossolo Húmico distrófico; SXd Háplico distrófico; $\mathrm{LVd}_{2}$, Latossolo Vermelho distrófico; $\mathrm{CXd}_{2}$, Cambissolo Háplico Tb distrófico; $\mathrm{SXd}_{2}$, Planossolo Háplico distrófico; $\mathrm{CXd}_{1}$, Cambissolo Háplico Tb distrófico; LVe-Latossolo Vermelho eutrófico. 
de calcário. Os aumentos do $\mathrm{pH}$ são conhecidos e atribuídos à neutralização dos íons $\mathrm{H}^{+}$pelos íons $\mathrm{OH}^{-}$, na fase sólida do solo, e à ocupação dos sítios de troca

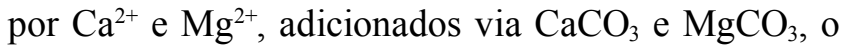

que provoca acréscimos dos níveis de $\mathrm{V}$, com o uso de doses crescentes de carbonato (Sousa et al., 2007). A magnitude do aumento dos teores de atributos de acidez é específica para cada solo, pois é regulada
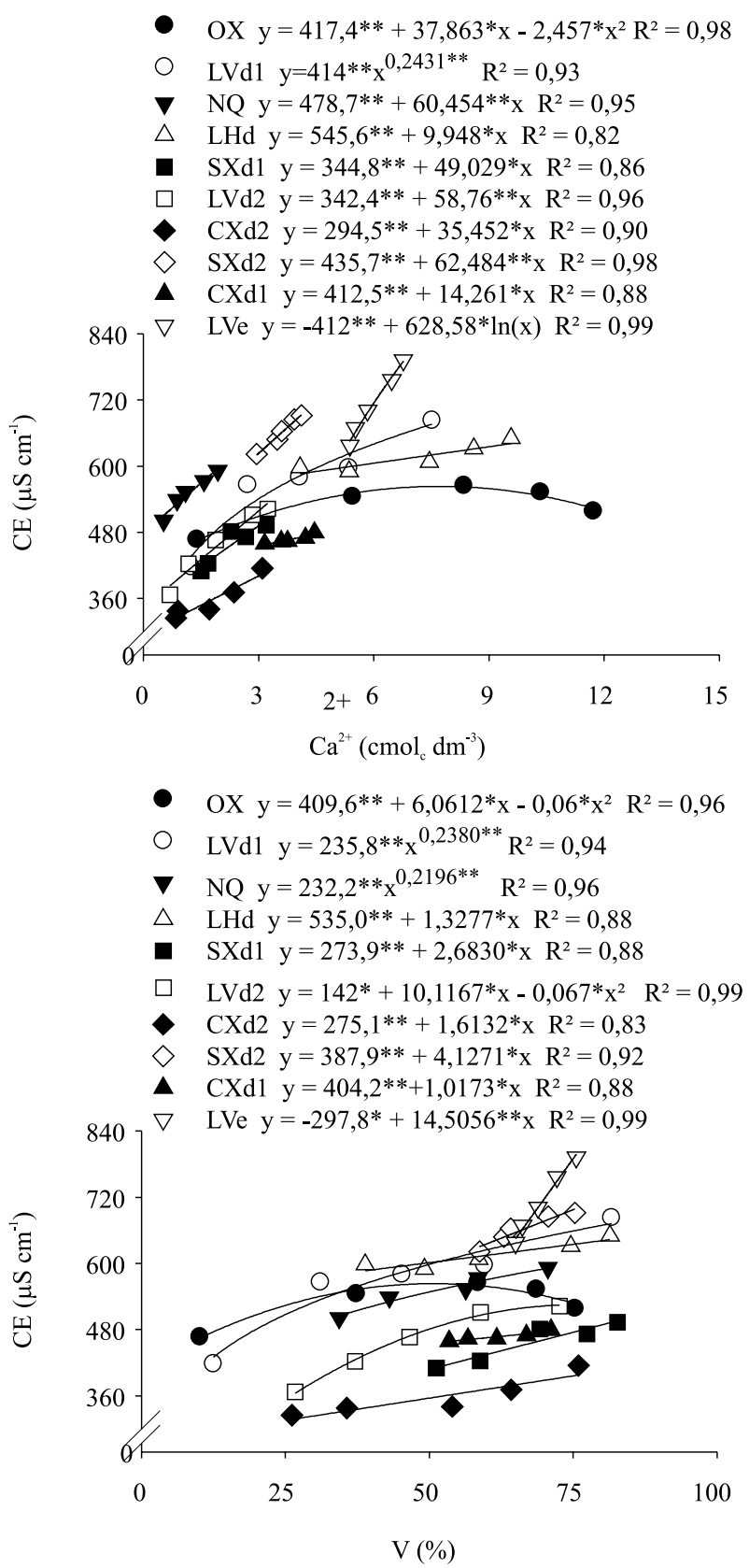
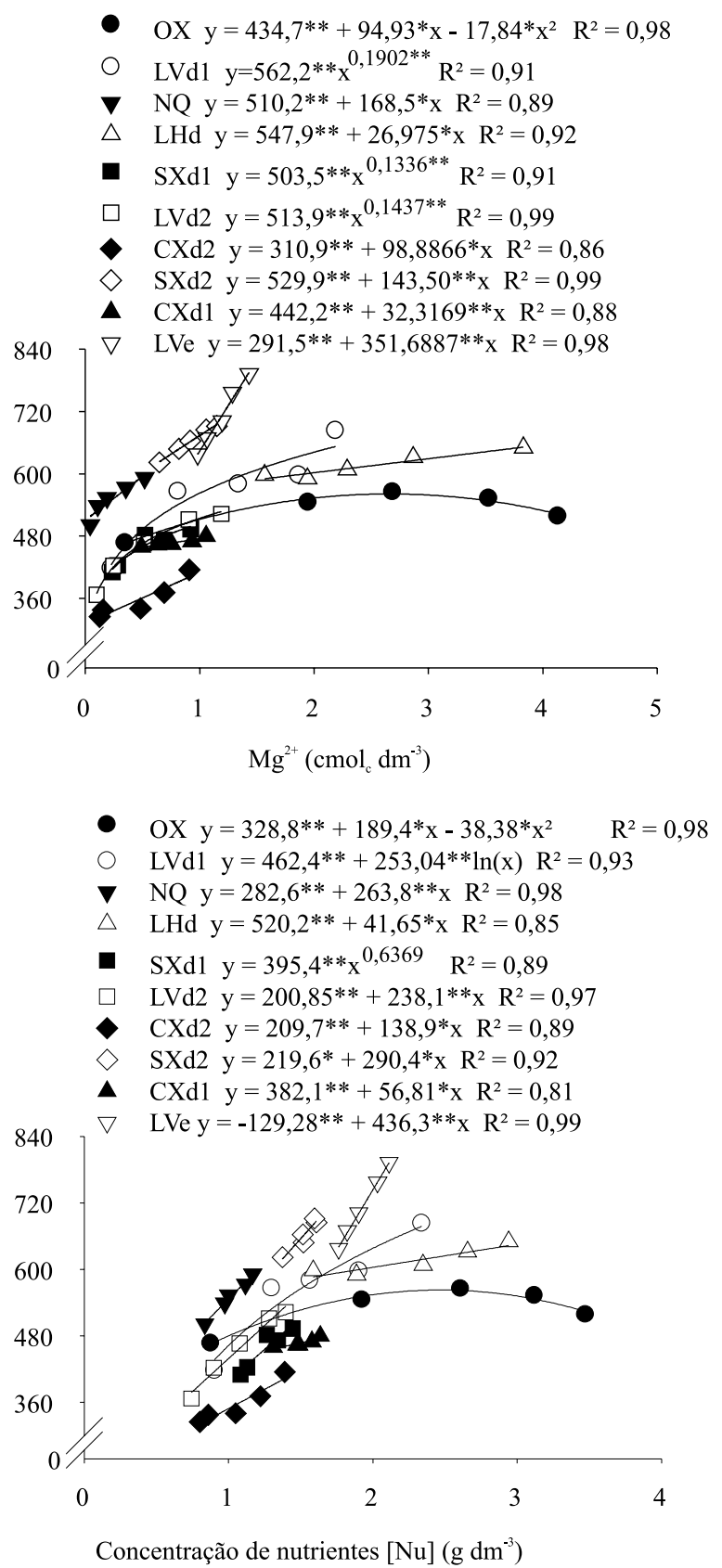

Figura 2. Relação de atributos de acidez $\left(\mathrm{Ca}^{2+}, \mathrm{Mg}^{2+}\right.$ e V) e das $[\mathrm{Nu}]$ - concentrações de $\mathrm{N}, \mathrm{P}, \mathrm{K}, \mathrm{Ca}, \mathrm{Mg}, \mathrm{S}, \mathrm{Zn}, \mathrm{Fe}, \mathrm{Mn}$, $\mathrm{Cu}$ e $\mathrm{B}-$, com a condutividade elétrica (CE), para os 10 solos investigados. * e**Significativo a 1 e 5\%, respectivamente, pelo teste F. OX, Organossolo Háplico; $\mathrm{LVd}_{1}$, Latossolo Vermelho distrófico; NQ, Neossolo Quartzarênico; LHd, Latossolo Húmico distrófico; $\mathrm{SXd}_{1}$, Planossolo Háplico distrófico; $\mathrm{LVd}_{2}$, Latossolo Vermelho distrófico; $\mathrm{CXd}_{2}$, Cambissolo Háplico Tb distrófico; $\mathrm{SXd}_{2}$, Planossolo Háplico distrófico; $\mathrm{CXd}_{1}$, Cambissolo Háplico Tb distrófico; LVe, Latossolo Vermelho eutrófico. 
pelos teores de argila e MO que determinam o seu poder tampão (Xu et al., 2012).

Os valores de CE para os 10 solos, em consequência dos níveis de calagem aplicados, variam de 325 a 792 $\mu \mathrm{S} \mathrm{cm}^{-1}$, o que caracteriza solos não salinizados. A CE se relaciona de forma positiva aos teores de $\mathrm{Ca}^{2+}$, $\mathrm{Mg}^{2+}$, aos níveis de $\mathrm{V}$ e às concentrações de nutrientes [Nu] (Figura 2). Segundo Fageria et al. (2010) e Prado \& Natale (2008), com a calagem, há elevação da disponibilidade de $\mathrm{Ca}^{2+}$ e $\mathrm{Mg}^{2+}$, mudanças no balanço das concentrações de $\mathrm{H}^{+}$e $\mathrm{OH}^{-}$em razão das mudanças do $\mathrm{pH}$, precipitação de $\mathrm{Al}^{3+}$, decomposição da $\mathrm{MO}$ e aumento da disponibilidade de $\mathrm{N}$ mineral e de $\mathrm{P}$. Todas essas mudanças podem explicar as magnitudes diferenciadas para cada solo quanto aos níveis de $\mathrm{CE}$.

Nos solos NQ, LHd, $\mathrm{SXd}_{1}, \mathrm{LVd}_{2}, \mathrm{CX}_{2}, \mathrm{SXd}_{2}, \mathrm{CXd}_{1}$, os dados obtidos ajustaram-se a modelos lineares, quando a $\mathrm{CE}$ foi relacionada com o teor de $\mathrm{Ca}^{2+}$. Os dados do $\mathrm{LVd}_{1}$ ajustaram-se ao modelo do tipo potência. A magnitude de variações de CE engloba valores de 9,9 a $63 \mu \mathrm{S} \mathrm{cm}^{-1}$, para cada $1 \mathrm{cmol}_{\mathrm{c}} \mathrm{dm}^{-3}$ de $\mathrm{Ca}^{2+}$ aumentado no solo pela calagem. No LVe, cujos dados se ajustaram ao modelo logarítmico, notase aumento de $115 \mu \mathrm{S} \mathrm{cm}^{-1}$, para cada $1 \mathrm{cmol}_{\mathrm{c}} \mathrm{dm}^{-3}$ de $\mathrm{Ca}^{2+}$ adicionado ao solo. No solo com maior teor de $\mathrm{MO}(\mathrm{OX})$, cujos dados se ajustaram ao modelo quadrático, o valor máximo alcançado de $\mathrm{CE}$ foi de $563 \mu \mathrm{S} \mathrm{cm}^{-1}$, para o teor de 7,7 $\mathrm{cmol}_{\mathrm{c}} \mathrm{dm}^{-3} \mathrm{de} \mathrm{Ca}^{2+}$. A partir deste valor máximo, a $\mathrm{CE}$ diminui com o aumento dos teores de $\mathrm{Ca}^{2+}$ no solo; isto sinaliza a precipitação de $\mathrm{Ca}^{2+}$ com outros ânions, o que implica a diminuição da concentração de íons na fase líquida e, provavelmente, a redução do fluxo de corrente elétrica e, por conseguinte, a CE do solo. Em relação ao $\mathrm{Ca}^{2+}$, seu excesso em solo pode levar à diminuição da $\mathrm{CE}$, quando ela ocorre, possivelmente, em razão da formação de sais insolúveis de Ca com outros co-íons, o que reduz a condução de corrente elétrica no solo (Tamir et al., 2013).

A magnitude dos aumentos de CE, em consequência dos teores de $\mathrm{Mg}^{2+}$ no solo, também foram específicas para cada solo, com ajustes lineares para o RQ, LHd, $\mathrm{CXd}_{2}, \mathrm{SXd}_{2}, \mathrm{CX}_{1}$ e LVe. A CE variou de 27 a 352 $\mu \mathrm{S} \mathrm{cm}{ }^{-1}$, para cada $1 \mathrm{cmol}_{\mathrm{c}} \mathrm{dm}^{-3}$ de $\mathrm{Mg}^{2+}$ aumentado com o uso de carbonato (Figura 2). Nos solos $\mathrm{LVd}_{1}$, $\mathrm{SXd}_{1}$ e $\mathrm{LVd}_{2}$, a amplitude de variação da $\mathrm{CE}$ englobou valores de 73 a $115 \mu \mathrm{S} \mathrm{cm}^{-1}$, para cada $1 \mathrm{cmol}_{\mathrm{c}} \mathrm{dm}^{-3}$ de $\mathrm{Mg}^{2+}$ aumentado. No OX, o modelo quadrático foi o que melhor se ajustou ao conjunto de dados, com o valor máximo de CE de $561 \mu \mathrm{S} \mathrm{cm}^{-1}$ para o teor em solo de 2,7 $\mathrm{cmol}_{\mathrm{c}} \mathrm{dm}^{-3} \mathrm{de} \mathrm{Mg}^{2+}$; a partir do valor máximo, os valores de CE são diminuídos com os aumentos dos teores de $\mathrm{Mg}^{2+}$. As amplitudes de variações da $\mathrm{CE}$,

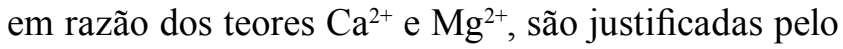
poder tampão que cada solo apresenta sobre o aumento da CE, que pode ser explicado pela MO, argila e CTC, e pelas reações de precipitação e de adsorção e de outros processos que retiram íons da fase líquida do solo. Este tamponamento da $\mathrm{CE}$ ocorre graças aos teores contrastantes de $\mathrm{MO}$, argila e de outros condicionantes que exercem influência sobre o poder tampão do solo (Xu et al., 2012; Heiniger et al., 2003). Além disso, o poder tampão de cada solo controla as variações de $\mathrm{pH}$ que, por sua vez, interferem nas reações de adsorção/ dessorção, precipitação/dissolução, complexação e oxirredução de nutrientes no solo (Meurer, 2007; Novais et al., 2007; Pavinato \& Rosolem, 2008), e, consequentemente, regulam a disponibilidade de nutrientes na solução do solo, alterando a CE.

$\mathrm{Na}$ Tabela 3, estão apresentados os teores de macro e micronutrientes, além do somatório das concentrações de nutrientes $\Sigma[\mathrm{Nu}]$, considerando-se os cinco níveis de calagem testados para os 10 solos investigados. É possível observar que as maiores modificações dos índices de fertilidade do solo se referem aos atributos de acidez modificados pelas doses crescentes de

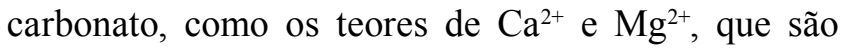
os principais responsáveis pelas modificações das concentrações de $[\mathrm{Nu}]$ e, consequentemente, da $\mathrm{CE}$. Apesar de os demais nutrientes terem sido adicionados em doses iguais, para os cinco níveis de calagem e para os diferente solos, para alcançar níveis adequados de crescimento de plantas, poucas alterações foram constatadas em atributos além dos de acidez do solo. As modificações dos atributos de acidez do solo são resultantes das alterações dos valores de $\mathrm{pH}$, do acréscimo dos níveis de cátions básicos e da neutralização dos ácidos, e da capacidade tampão de cada solo para a acidez, que é regulada pelos teores de argila e MO de cada solo (Sousa et al., 2007; Raij, 2011).

As alterações da $\mathrm{CE}$, em razão dos valores de $\mathrm{V}$ e $[\mathrm{Nu}]$, ocorrem principalmente graças aos aumentos dos teores de $\mathrm{Ca}$ e $\mathrm{Mg}$ no solo, já que os demais nutrientes foram adicionados em quantidades iguais. A magnitude desses processos depende dos fatores 
Tabela 3. Teores de macro e micronutrientes, em consequência dos cinco níveis de calagem nos 10 solos investigados.

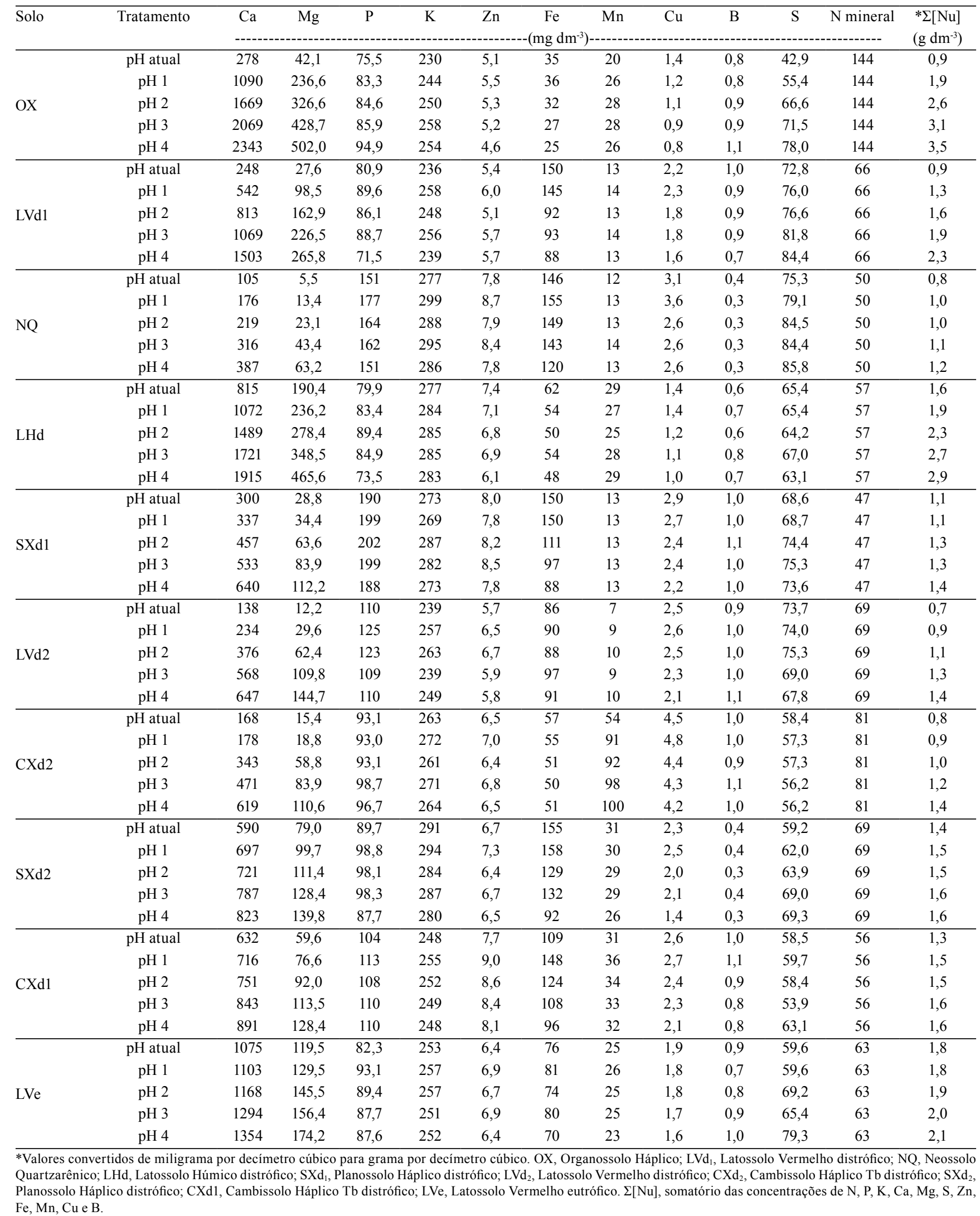


mencionados e da quantidade de íons solúveis aptos a conduzir corrente elétrica no solo. Em geral, há relação direta entre a $\mathrm{CE}$ e os atributos de acidez do solo, como consequência da aplicação de níveis crescentes de calagem. Moral et al. (2010) verificaram correlações entre $\mathrm{CE}$ e pH, em amostras de solo de 33 ha cultivados com canola, com medição automática de CE do solo à profundidade de $0-30 \mathrm{~cm}$. Estes resultados estão de acordo com trabalho realizado por Valarini et al. (2007), que mostraram um forte grau de associação entre $\mathrm{pH}, \mathrm{SB}, \mathrm{V}$ e $\mathrm{CE}$ do solo.
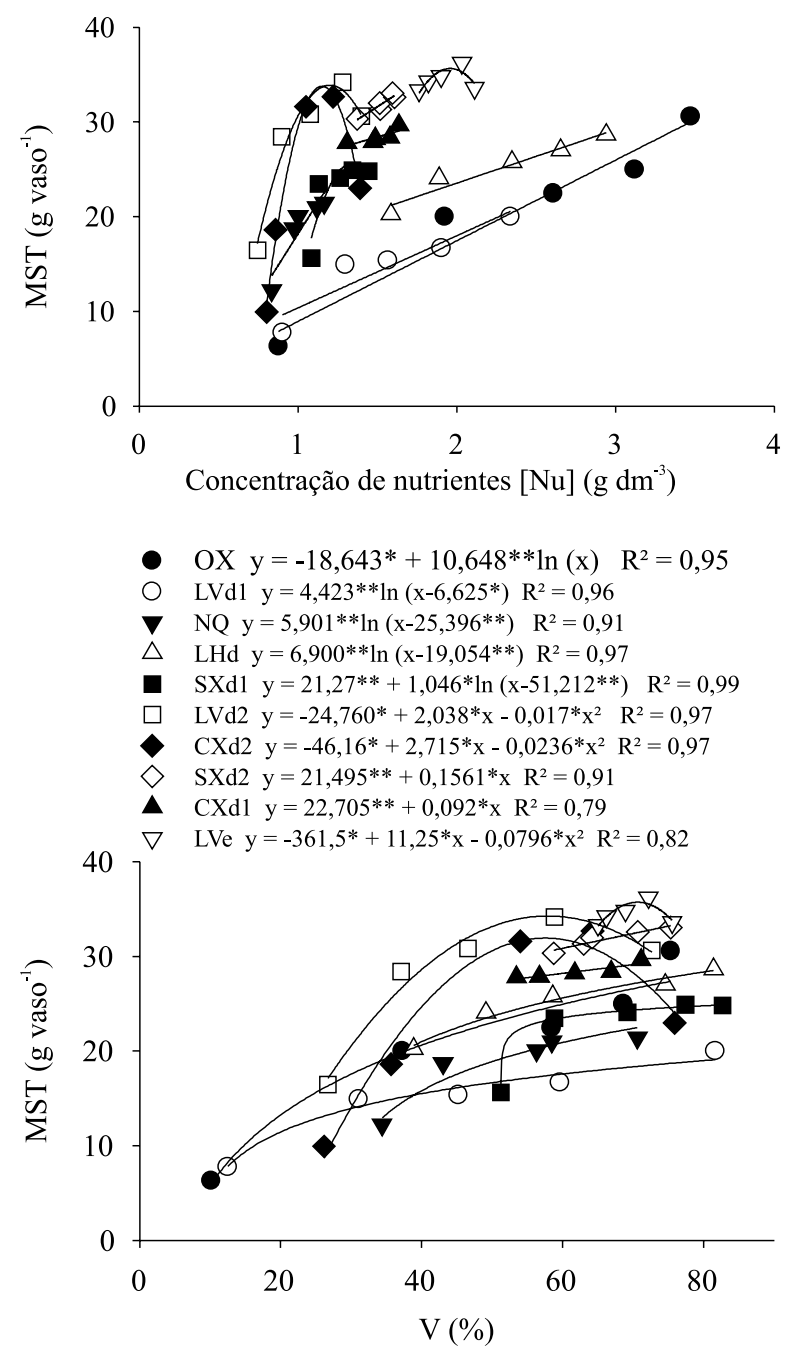

A massa de matéria seca total (MST) relacionou-se à saturação por bases, e esses dados foram ajustados ao modelo do tipo logarítmico, para os solos OX, $\mathrm{LVd}_{1}, \mathrm{NQ}, \mathrm{LHd}$ e $\mathrm{SXd}_{1}$; ajustes do tipo quadrático foram verificados para o $\mathrm{LVd}_{2}, \mathrm{CXd}_{2}$ e $\mathrm{LVe}$, e as equações lineares foram ajustadas aos dados do $\mathrm{SXd}_{2}$ e $\mathrm{CXd}_{1}$ (Figura 3). Os aumentos da MST resultam, principalmente, da neutralização da acidez do solo, que possibilita maior disponibilidade e absorção de nutrientes (Vitti et al., 2006) e aumentos dos teores de $\mathrm{Ca}^{2+}$ e $\mathrm{Mg}^{2+}$ no solo, em consequência da aplicação

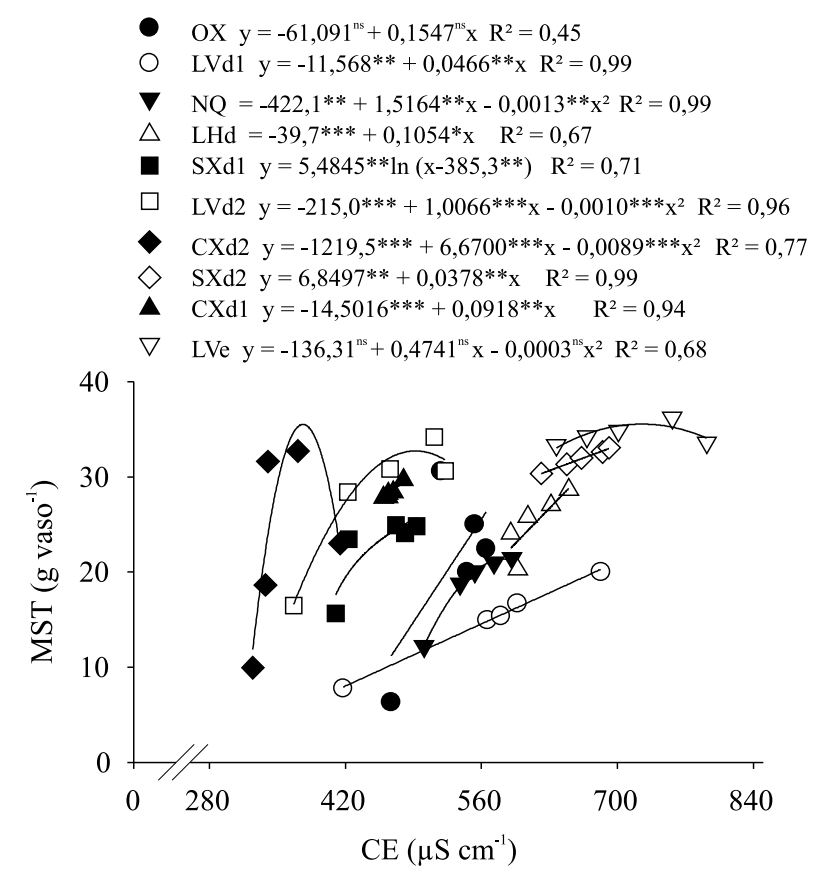

Figura 3. Relação da concentração de nutrientes [Nu], saturação por bases (V) e condutividade elétrica (CE) do solo, com a produção de massa de matéria seca total (MST) de plantas de milho, para os 10 solos investigados. ${ }^{\text {ns }}$ Não significativo. $*, * * \mathrm{e}^{* * *}$ Significativo a 1, 5 e 10\%, respectivamente, pelo teste F. OX, Organossolo Háplico; $\mathrm{LVd}_{1}$, Latossolo Vermelho distrófico; NQ, Neossolo Quartzarênico; LHd, Latossolo Húmico distrófico; $\mathrm{SXd}_{1}$, Planossolo Háplico distrófico; $\mathrm{LVd}_{2}$, Latossolo Vermelho distrófico; $\mathrm{CXd}_{2}$, Cambissolo Háplico Tb distrófico; $\mathrm{SXd}_{2}$, Planossolo Háplico distrófico; $\mathrm{CXd}_{1}$, Cambissolo Háplico Tb distrófico; LVe, Latossolo Vermelho eutrófico. 
de carbonatos, já que os demais nutrientes foram supridos em quantidades ideais para o crescimento do milho. As relações entre os valores de V e a MST, específicas ao solo, ocorrem principalmente graças às variações da textura e dos teores de $\mathrm{MO}$, que regulam a taxa de mineralização de $\mathrm{MO}$ e, por conseguinte, a disponibilidade de nutrientes para as plantas.

Em face dos resultados constatados no presente estudo, a CE pode ser utilizada como mais um índice para a verificação dos efeitos da calagem sobre o solo e seus processos, e como potencial índice de fertilidade do solo, pois há maior fluxo de corrente elétrica com o aumento da concentração de nutrientes no solo. A CE permite, indiretamente, inferir a quantidade de solutos inorgânicos e orgânicos, disponíveis na solução aquosa e associados aos coloides do solo (Heiniger et al., 2003), e pode, portanto, predizer a quantidade de nutrientes potencialmente disponíveis para as plantas, considerando-se a especificidade de relações para cada solo (Brevik et al., 2006; Peralta \& Costa, 2013). Assim, a CE pode ser utilizada como preditora do crescimento do milho e como potencial índice de fertilidade do solo para se avaliarem os efeitos da calagem.

\section{Conclusões}

1. A condutividade elétrica aumenta em razão do acréscimo dos níveis de calagem, e há relação positiva entre os teores de $\mathrm{Ca}^{2+}, \mathrm{Mg}^{2+}$, saturação por bases e $\mathrm{pH}$, para cada classe de solo em particular.

2. A condutividade do solo explica grande parte da variação da massa de matéria seca de milho e se relaciona positivamente à concentração de nutrientes, que também prediz o crescimento do milho, em consequência dos níveis de carbonato adicionados ao solo.

3. Não há uma equação universal que explique as variações em produção de massa de matéria seca de milho, quando se consideram a condutividade elétrica e a concentração de nutrientes no solo como preditoras do crescimento da cultura em vaso.

\section{Agradecimentos}

Ao Conselho Nacional de Desenvolvimento Científico e Tecnológico (CNPq), pelo financiamento da pesquisa (processo número 308592/2011-5) e concessão de bolsas; às bolsistas de iniciação científica Laís Botelho de Lima e Laura Beatriz Batista de
Melo, pela ajuda na realização de parte das análises laboratoriais.

\section{Referências}

AMARAL, A.S.; ANGHINONI, I.; HINRICHS, R.; BERTOL, I. Movimentação de partículas de calcário no perfil de um Cambissolo em plantio direto. Revista Brasileira de Ciência do Solo, v.28, p.359-367, 2004. DOI: 10.1590/S0100-06832004000200014.

BREVIK, E.C.; FENTON, T.E.; LAZARI, A. Soil electrical conductivity as a function of soil water content and implications for soil mapping. Precision Agriculture, v.7, p.393-404, 2006. DOI: 10.1007/s11119-006-9021-X.

CHAVES, L.H.G.; QUEIROZ, M.F.; OLIVEIRA, E.L. de; SANTANA, E.F. Efeito do carbonato de cálcio na dispersão de argila de um Latossolo. Agropecuária Técnica, v.18, p.1-7, 1997.

CLAESSEN, M.E.C. (Org.). Manual de métodos de análise de solo. 2.ed. rev. e atual. Rio de Janeiro: Embrapa-CNPS, 1997. 212p. (Embrapa-CNPS. Documentos, 1).

CORWIN, D.L.; LESCH, S.M. Characterizing soil spatial variability with apparent soil electrical conductivity: I. survey protocols. Computers and Electronics in Agriculture, v.46, p.103-133, 2005. DOI: 10.1016/j.compag.2004.11.002.

FAGERIA, N.K.; SANTOS, A.B. dos; MOREIRA, A. Yield, nutrient uptake, and changes in soil chemical properties as influenced by liming and iron application in common bean in a no-tillage system. Communications in Soil Science and Plant Analysis, v.41, p.1740-1749, 2010. DOI: 10.1080/00103624.2010.489137.

FERNANDES, L.A.; RAMOS, S.J.; VALADARES, S.V.; LOPES, P.S.N.; FAQUIN, V. Fertilidade do solo, nutrição mineral e produtividade da bananeira irrigada por dez anos. Pesquisa Agropecuária Brasileira, v.43, p.1575-1581, 2008. DOI: 10.1590/ S0100-204X2008001100017.

HEINIGER, R.W.; MCBRIDE, R.G.; CLAY, D.E. Using soil electrical conductivity to improve nutrient management. Agronomy Journal, v.95, p.508-519, 2003. DOI: 10.2134/ agronj2003.5080.

JOHNSON, C.K.; ESKRIDGE, K.M.; CORWIN, D.L. Apparent soil electrical conductivity: applications for designing and evaluating field-scale experiments. Computers and Electronics in Agriculture, v.46, p.181-202, 2005. DOI: 10.1016/j. compag.2004.12.001.

LESCH, S.M.; CORWIN, D.L.; ROBINSON, D.A. Apparent soil electrical conductivity mapping as an agricultural management tool in arid zone soils. Computers and Electronics in Agriculture, v.46, p.351-378, 2005. DOI: 10.1016/j.compag.2004.11.007.

LUND, E.D.; WOLCOTT, M.C.; HANSON, G.P. Applying nitrogen site-specifically using soil electrical conductivity maps and precision agriculture technology. Scientific World, v.1, p.767-776, 2001. DOI: 10.1100/tsw.2001.95.

MEURER, E.J. Fatores que influenciam o crescimento e o desenvolvimento das plantas. In: NOVAIS, R.F.; ALVAREZ V., V.H.; BARROS, N.F. de; FONTES, R.L.F.; CANTARUTTI, R.B.; 
NEVES, J.C.L. (Ed.). Fertilidade do solo. Viçosa: Sociedade Brasileira de Ciência do Solo, 2007. p.65-90.

MCBRIDE, R.A.; SHRIVE, S.C.; GORDON, A.M. Estimating forest soil quality from terrain measurements of apparent electrical conductivity. Soil Science Society of America Journal, v. 54, p.290-293, 1990. DOI: 10.2136/ sssaj1990.03615995005400010047x.

MORAL, F.J.; TERRÓN, J.M.; SILVA, J.R.M. da. Delineation of management zones using mobile measurements of soil apparent electrical conductivity and multivariate geostatistical techniques. Soil and Tillage Research, v.106, p.335-343, 2010. DOI: 10.1016/j. still.2009.12.002.

NOVAIS, R.F.; ALVAREZ V., V.H.; BARROS, N.F. de; FONTES, R.L.F.; CANTARUTTI, R.B.; NEVES, J.C.L.. Fertilidade do solo. Viçosa: Sociedade Brasileira de Ciência do Solo, 2007. $1017 \mathrm{p}$.

NOVAIS, R.F.; NEVES, J.C.L.; BARROS, N.F. Ensaio em ambiente controlado. In: OLIVEIRA, A.J.; GARRIDO, W.E.; ARAUJO, J.D. de; LOURENÇO, S. (Coord.). Métodos de pesquisa em fertilidade do solo. Brasília: Embrapa-SEA, 1991. p.189-253. (Embrapa-SEA. Documentos, 3).

PAVINATO, P.S.; ROSOLEM, C.A. Disponibilidade de nutrientes no solo - decomposição e liberação de compostos orgânicos de resíduos vegetais. Revista Brasileira de Ciência do Solo, v.32, p.911-920, 2008. DOI: 10.1590/S0100-06832008000300001.

PERALTA, N.R.; COSTA, J.L. Delineation of management zones with soil apparent electrical conductivity to improve nutrient management. Computers and Electronics in Agriculture, v.99, p.218-226, 2013. DOI: 10.1016/j.compag.2013.09.014.

PERALTA, N.R.; COSTA, J.L.; BALZARINI, M.; FRANCO, M.C.; CÓRDOBA, M.; BULLOCK, D. Delineation of management zones to improve nitrogen management of wheat. Computers and Electronics in Agriculture, v.110, p.103-113, 2015. DOI: 10.1016/j.compag.2014.10.017.

PRADO, R. de M.; NATALE, W. Effect of liming on the mineral nutrition and yield of growing guava trees in a typic Hapludox soil. Communications in Soil Science and Plant Analysis, v.39, p.2191-2204, 2008. DOI: 10.1080/00103620802137613.

RAIJ, B. van. Fertilidade do solo e manejo de nutrientes. Piracicaba: IPNI, 2011. 420p.
SANTOS, H.G. dos; JACOMINE, P.K.T.; ANJOS, L.H.C. dos; OLIVEIRA, V.A. de; LUMBRERAS, J.F.; COELHO, M.R.; ALMEIDA, J.A. de; CUNHA, T.J.F.; OLIVEIRA, J.B. de. Sistema brasileiro de classificação de solos. 3.ed. rev. e ampl. Brasília: Embrapa, 2013. 353p.

SILVA, C.A.; VALE, F.R.; GUILHERME, L.R.G. Nitrificação em latossolos da região Sul de Minas Gerais: efeito da acidez do solo. Ciência e Prática, v.18, p.388-394, 1994.

SILVA, F.C. da (Ed.). Manual de análises químicas de solos, plantas e fertilizantes. 2.ed. rev. e atual. Brasília: Embrapa Informática Tecnológica; Rio de Janeiro: Embrapa Solos, 2009. 627p.

SOUSA, D.M.G. de; MIRANDA, L.N. de; OLIVEIRA, S.A. de. Acidez do solo e sua correção. In: NOVAIS, R.F.; ALVAREZ V., V.H.; BARROS, N.F. de; FONTES, R.L.F.; CANTARUTTI, R.B.; NEVES, J.C.L. (Ed.). Fertilidade do solo. Viçosa: Sociedade Brasileira de Ciência do Solo, 2007. p.206-266.

TAMIR, G.; SHENKER, M.; HELLER, H.; BLOOM, P.R.; FINE, P.; BAR-TAL, A. Organic N mineralization and transformations in soils treated with animal waste in relation to carbonate dissolution and precipitation. Geoderma, v.209/210, p.50-56, 2013. DOI: 10.1016/j.geoderma.2013.05.028.

VALARINI, P.J.; FRIGHETTO, R.T.S.; SCHIAVINATO, R.J.; CAMPANHOLA. C.; SENA, M.M. de; BALBINOT, L.; POPPI, R.J. Análise integrada de sistemas de produção de tomateiro com base em indicadores edafobiológicos. Horticultura Brasileira, v.25, p.60-67, 2007. DOI: 10.1590/ S0102-05362007000100012.

VITTI, G.C.; LIMA, E.; CICARONE, F. Cálcio, magnésio e enxofre. In: FERNANDES, M.S. (Ed.). Nutrição mineral de plantas. Viçosa: Sociedade Brasileira de Ciência do Solo, 2006. p.299-325.

XU, R.-K.; ZHAO, A.-Z.; YUAN, J.-H.; JIANG, J. pH buffering capacity of acid soils from tropical and subtropical regions of China as influenced by incorporation of crop straw biochars. Journal of Soils and Sediments, v.12, p.494-502, 2012. DOI: 10.1007/s11368-012-0483-3.

YAO, H.Y.; BOWMAN, D.; RUFTY, T.; SHI, W. Interactions between $\mathrm{N}$ fertilization, grass clipping addition and $\mathrm{pH}$ in turf ecosystems: implications for soil enzyme activities and organic matter decomposition. Soil Biology and Biochemistry, v.41, p.1425-1432, 2009. DOI: 10.1016/j.soilbio.2009.03.020.

Recebido em 10 de março de 2016 e aprovado em 21 de junho de 2016 